\title{
Optimal growth conditions for basidiospore germination and morphogenesis of Philippine wild strain of Lentinus tigrinus (Bull.) Fr.
}

\section{Dulay $\mathrm{RMR}^{1 *}$, Cabrera $\mathrm{EC}^{2}$, Kalaw $\mathrm{SP}^{1}$ and Reyes $\mathrm{RG}^{1}$}

\author{
${ }^{1}$ Center for Tropical Mushroom Research and Development, Department of Biological Sciences, College of Arts and \\ Sciences, Central Luzon State University, Science City of Muñoz, Nueva Ecija, Philippines \\ ${ }^{2}$ Department of Biology, College of Science, De La Salle University, Taft Avenue, Manila, Philippines
}

Dulay RMR, Cabrera EC, Kalaw SP, Reyes RG 2012 - Optimal growth conditions for basidiospore germination and morphogenesis of Philippine wild strain of Lentinus tigrinus (Bull.) Fr. Mycosphere 3(6), 926-933, Doi 10.5943 /mycosphere/3/6/6

Lentinus tigrinus is a basidiomycetous fungus that is usually found growing in clusters on fallen logs of the forest. This mushroom is considered as the local counterpart of shiitake (L. edodes), since it is endemically growing in the tropical countries such as the Philippines. In our intention to develop production technology for this mushroom, we determined the influence of nutritional (local culture media) and physical $(\mathrm{pH}$, aeration, illumination and temperature) factors for basidiospore germination and morphogenesis of wild strain of L. tigrinus. Basidiospores of L. tigrinus germinated efficiently in a submerged culture with potato sucrose broth $(\mathrm{pH} 7.5)$ incubated in a lighted air-conditioned room $\left(23^{\circ} \mathrm{C}\right)$ with a mean of $91.33 \%$ after $10 \mathrm{~h}$ of incubation. A peculiar type of germination process was evident as the spore coat was retained, elongated and eventually became part of the hypha. A sequence of significant developmental stages; mycelial coat thickening, swelling formation, browning and primordial initiation arises prior to basidiomata maturation and basidiospores liberation. L. tigrinus is a further addition to the list of Philippine wild edible mushrooms with great potential for cultivation.

Key words - basidiospores - Lentinus tigrinus - morphogenesis - nutritional requirement

\section{Article Information}

Received 4 September 2012

Accepted 8 November 2012

Published online 19 November 2012

*Corresponding author: Rich Milton R. Dulay - e-mail - richmiltondulay@yahoo.com

\section{Introduction}

Mushroom production in the Philippines is progressively improving because Filipinos are becoming acquainted of the good taste and healthful benefits of consuming mushrooms. In Central Luzon, only few basidiomycetes are grown commercially on locally available substrates. These include Pleurotus florida, $P$. sajor-caju, P. ostreatus, Volvariella volvacea, Ganoderma lucidum and Auricularia polytricha. Thus, harnessing the potential of other wild mycological resources for industrial cultivation is imperative.

Lentinus possesses a lamellate hymenophore and white basidiospores which has traditionally been considered in the family Tricholomataceae (Miller, 1973). However, the presence of dimitic and amphimitic hyphal system supports the placement of this genus in family Polyporaceae (Pegler, 1983; Singer, 1986). In the Philippines, there are two species of Lentinus, namely: L. sajor-caju and $L$. 
tigrinus. Their suitability in the tropical conditions of the country indicates that these mushrooms can be considered as the local counterpart of shiitaki (Lentinula edodes). Lentinus tigrinus is a wood rotting basidiomycete with leathery flesh, strong aroma and taste that makes it applicable for gourmet purposes. In previous studies, we found that this mushroom contained high amounts of carbohydrates, proteins, fibers and minerals. It also exhibits hypoglycemic effect in alloxaninduced mice (Dulay et al., 2012a) and antibacterial activity (Dulay et al., 2012b). Furthermore, acute single oral toxicity test in ICR mice confirmed that $L$. tigrinus is an edible mushroom species (Dulay et al., 2011). Given the enormous nutraceutical potential of $L$. tigrinus, understanding the fundamental aspects on growth and development for the successful production technology of this species is important.

In the present work, a naturally occurring strain of L. tigrinus was collected from the wild and the optimal growth conditions for basidiospore germination and morphogenesis determined.

\section{Methods}

\section{Source of basidiospores}

Wild fruiting bodies of $L$. tigrinus were obtained from Central Luzon State University, Science City of Muñoz, Nueva Ecija. The basidiospores of L. tigrinus were collected from the healthy basidiocarp. These were obtained by laying down the open basidiocarp in a sterile Petri plate previously lined with filter paper. The plates were incubated for $12 \mathrm{~h}$ at ambient room temperature to allow the detachment of the basidiospores from the basidium. The collected basidiospores were pre-soaked in a test tube containing $9 \mathrm{ml}$ distilled water, and incubated in a water bath at $40^{\circ} \mathrm{C}$ for $1 \mathrm{~h}$. This spore suspension was cooled and $0.1 \mathrm{mg} / \mathrm{ml}$ of streptomycin sulphate was added to prevent bacterial contamination. The spore concentration was determined using a haemocytometer.

\section{Influence of nutritional factors}

The influence of nutritional factors on the germination of basidiospores was evaluated using different broth culture media: coconut water from mature coconut (Cocos nucifera), rice bran D1 (class A) decoction (50g of Oryza sativa/L of water), local yellow corn grit decoction $(50 \mathrm{~g}$ of Zea mays/L of water) and potato sucrose broth $(250 \mathrm{~g}$ of Solanum tuberosum $/ \mathrm{L}$ of water $+10 \mathrm{~g}$ of white table sugar). Broth media were adjusted to $\mathrm{pH} 6$ (optimum $\mathrm{pH}$ for wood rotting fungi) and sterilized prior to inoculation, where $0.1 \mathrm{ml}$ containing $7.5 \times 10^{5} / \mathrm{ml}$ of basidiospores from the spore suspension was transferred into each of the sterile tubes with $1 \mathrm{ml}$ of the different broth media as submerged culture. Each set-up comprised two replicates. The inoculated broth media were incubated at $32^{\circ} \mathrm{C}$ under alternating light and dark condition. Percentage germination (swelling and elongation of the basidiospores) of 100 spores from randomly captured images were taken with a Moticam 2300 (Motic Incorporation Ltd.) was recorded after 7 and $10 \mathrm{~h}$ of incubation with the aid of haemocytometer under a compound microscope. Germinated spore sampling from each tube was replicated 3 times.

\section{Influence of physical factors}

\section{$p H$}

The most appropriate broth culture medium was used to evaluate the germination of spores as affected by 3 important physical factors namely: $\mathrm{pH}$ level, temperature and illumination. The best broth medium was adjusted to varying $\mathrm{pH}$ levels (6.0-8.0 at 0.5 intervals), and sterilized in $1 \mathrm{ml}$ volume in separate tubes. These were inoculated with 0.1 $\mathrm{ml}$ from the spore suspension with $7.5 \times 10^{5} / \mathrm{ml}$ of basidiospores and incubated at room temperature. Percentage germination was recorded.

\section{Illumination}

One hundred microliter with $7.5 \times$ $10 \% \mathrm{ml}$ of basidiospores from the spore suspension was aseptically inoculated into $1 \mathrm{ml}$ sterilized broth medium with the optimum $\mathrm{pH}$ level. These were incubated in lighted (30 footcandles) and full dark conditions at room temperature. To provide full dark condition, tubes were wrapped with aluminum foil. Percentage germination was recorded after $7 \mathrm{~h}$ and $10 \mathrm{~h}$ of incubation. 
Table 1 Influence of nutritional and physical factors on the germination of basidiospore of $L$. tigrinus after 7 and 10 hours of incubation.

\begin{tabular}{lll}
\hline Nutritional / Physical & \multicolumn{2}{c}{ Germination (\%) } \\
Factors & $\mathbf{7}^{\text {th }}$ Hour & $\mathbf{1 0}^{\text {th }}$ Hour \\
\hline Broth media & & \\
Rice bran broth & $64.67 \pm 5.77^{\mathrm{b}}$ & $74.67 \pm 8.33^{\mathrm{b}}$ \\
Corn grit broth & $60.00 \pm 5.29^{\mathrm{b}}$ & $68.00 \pm 7.21^{\mathrm{b}}$ \\
Coconut water & $67.33 \pm 3.05^{\mathrm{b}}$ & $74.67 \pm 7.57^{\mathrm{b}}$ \\
Potato sucrose broth & $84.00 \pm 5.29^{\mathrm{a}}$ & $87.33 \pm 1.15^{\mathrm{a}}$ \\
$\mathbf{~ p H}$ & & \\
6.0 & $79.67 \pm 2.08^{\mathrm{a}}$ & $84.33 \pm 0.58^{\mathrm{b}}$ \\
6.5 & $65.33 \pm 2.31^{\mathrm{b}}$ & $70.33 \pm 2.52^{\mathrm{c}}$ \\
7.0 & $61.00 \pm 1.00^{\mathrm{c}}$ & $64.00 \pm 1.73^{\mathrm{d}}$ \\
7.5 & $82.00 \pm 1.00^{\mathrm{a}}$ & $88.67 \pm 0.58^{\mathrm{a}}$ \\
8.0 & $62.67 \pm 2.08^{\mathrm{bc}}$ & $66.33 \pm 3.06^{\mathrm{d}}$ \\
Illumination & $79.33 \pm 3.06^{\mathrm{a}}$ & $88.00 \pm 4.00^{\mathrm{a}}$ \\
Lighted $(30$ footcandles $)$ & $63.33 \pm 3.06^{\mathrm{b}}$ & $65.33 \pm 4.16^{\mathrm{b}}$ \\
Complete darkness & & \\
Temperature & $50.00 \pm 3.46^{\mathrm{c}}$ & $54.00 \pm 5.29^{\mathrm{c}}$ \\
Room temperature $\left(32^{\circ} \mathrm{C}\right)$ & $86.00 \pm 2.00^{\mathrm{a}}$ & $91.33 \pm 3.06^{\mathrm{a}}$ \\
Air-conditioned $\left(23^{\circ} \mathrm{C}\right)$ & $67.33 \pm 11.72^{\mathrm{b}}$ & $73.33 \pm 12.22^{\mathrm{b}}$ \\
\hline Refrigerated $\left(9^{\circ} \mathrm{C}\right)$ & &
\end{tabular}

(In Table: Values are the mean \pm SD of basidiospore germination, and means having the same letter of superscript in the same column are insignificantly different from each other at $5 \%$ level of significance.)

\section{Temperature}

The most appropriate medium, $\mathrm{pH}$ and illumination were used for the evaluation of optimum temperature. Tubes with best medium and optimum $\mathrm{pH}$ inoculated with $7.5 \times 10^{5} / \mathrm{ml}$ of basidiospores were incubated at optimum illumination with different temperature conditions; room temperature $\left(32^{\circ} \mathrm{C}\right)$, airconditioned $\left(23^{\circ} \mathrm{C}\right)$ and refrigerated $\left(9^{\circ} \mathrm{C}\right)$. Percentage germination of spores was again recorded after 7 and $10 \mathrm{~h}$ of incubation. Each treatment comprised two tubes, from which three samplings were made per tube for the determination of basidiospore germination.

\section{Process of basidiospore germination}

To observe the process of germination of basidiospores and formation of hypha, the best medium containing basidiospores was incubated under optimum physical conditions and periodically observed every 2 hours under a compound microscope. The percentage basidiospores undergoing swelling, elongation, branching, anastomosis, septation and clamp connection was determined at the different stages of growing hypha. Moticam 2300 was used to document the process.

\section{Developmental stages of basidiocarp formation}

The healthy fruit body was aseptically tissue cultured into potato dextrose agar plate. This was incubated at room temperature to allow mycelial growth. Agar blocks were inoculated in sterilized palay seeds and allowed for mycelial ramification. After full colonization, grains were aseptically inoculated into sterilized fruiting bags (polypropylene) containing compacted rice straw-sawdust based substrate formulations. Fruiting bags were incubated at room temperature until the culture was completely ramified by mycelia. The fully ramified bags were opened to allow fruiting initials to develop into mature basidiocarp. The developmental stages of fruit body formation were monitored and photo-documented.

The $\mathrm{SAS}^{\circledR} 9.1$ program was used for analysis. Data were analyzed using Analysis of Variance and treatment means were compared using Least Significant Difference at 5\% level of significance. T-test was used for the comparison of data with only two treatments. 


\section{Results and Discussion}

Influence of nutritional factors on the germination of basidiospores of L. tigrinus

The germination of spores marks the start of the life cycle of a mushroom. The successful germination of the dormant basidiospores is influenced by environmental conditions and nutrition. Cultivated mushrooms require optimal conditions for luxuriant growth (Thongklang et al., 2010). In this study, the basidiospores of L. tigrinus were cultured in four local culture media namely: rice bran broth, corn grit broth, coconut water and potato sucrose broth. The influence of nutritional factors on the germination of basidiospore of L. tigrinus after 7 and 10 hours of incubation are presented in Table 1. The highest percentage germination was obtained with the potato sucrose broth with means of $84.00 \%$ and $87.33 \%$ after 7 and 10 hours, respectively. These were significantly higher $(p<0.05)$ when compared to those in the three other media. The lowest percentage germination was noted in corn grit broth with means of $60 \%$ and $68.00 \%$ after 7 and 10 hours, respectively. These however, did not differ significantly from those in rice bran and coconut water. These results suggest that the germination of basidiospores is influenced by the kind of broth medium. The large amount of carbohydrate in potato $(21.6 \mathrm{~g}$ in $100 \mathrm{~g}$ of potato) as reported by Velangi and Wolever (2001) activates the germination of basidiospores. Niederpruem and Dennen (1966) revealed the variety of carbohydrates that stimulate the germination $S$. commune after 15-20 hours of incubation. These include glycogen, turanose, cellobiose, maltose, sucrose, glucose, fructose, mannose, galactose and xylose. Although these carbohydrates are also constituents of the other media evaluated, the levels of nutrients vary as these are all from natural sources. Klomklung et al. (2012) reported that media derived from the different sources such as soy bean, mung bean, red bean, black bean and sorghum could provide efficient growth of $P$. giganteus. The low percentages germination of basidiospores in corn grit broth and rice bran broth could be explained by the possible presence of inhibitory compounds that may interfere with the germination process.
Niederpruem and Dennen, (1966) enumerated compounds that inhibit the germination of basidiospores of $S$. commune namely: cycloheximide, L-ethionine, $p$-fluoro-DLphenylalanine, sodium azide, 2,4dinitrophenol, phenylmercuric acetate and 2deoxy-D-glucose. Moreover, this favourable germination of L. tigrinus spores in potato sucrose broth may also be explained by the buffering capacity of this medium to maintain the optimum conditions for germination.

\section{Influence of physical factors on the germination of basidiospores of L. tigrinus}

After establishing the optimum nutritional requirement for successful basidiospore germination, environmental conditions such as $\mathrm{pH}$ (acidity and basity) of the substrate, illumination and temperature were evaluated. Table 1 also presents the mean percentages basidiospore germination of $L$. tigrinus at different $\mathrm{pH}$ levels, illumination and temperature conditions. Potato sucrose broth with $\mathrm{pH}$ of 7.5 recorded the highest percentage germination with means of $82.00 \%$ and $88.67 \%$ after 7 hours and 10 hours, respectively. The mean percentage germination after 10 hours was significantly higher $(\mathrm{p}<0.05)$ when compared to other $\mathrm{pH}$ levels. These results agree with the previous findings of Bulseco et al. (2005) who reported that the optimum $\mathrm{pH}$ for germination of basidiospores for $S$. commune is $\mathrm{pH}$ 7.5. On the other hand, although it was noted that the mean percentage germination after 7 hours at $\mathrm{pH} 7.5$ was higher compared to that of $\mathrm{pH} 6$, the difference was not statistically significant. The lowest percentage germination was noted in potato sucrose broth with $\mathrm{pH} 7.0$ with mean percentages germination of $61.00 \%$ and $64.00 \%$ after 7 hours and 10 hours, respectively.

Aside from $\mathrm{pH}$, illumination or light requirement is another important environmental factor to be considered in mushroom production. Thus, the influence of illumination on basidiospores germination was also investigated. Basidiospores incubated in lighted condition (30 footcandles) significantly obtained higher percentage germination with means of $79 \%$ and $88 \%$ after 7 hours and 10 hours, respectively. This result implies that 


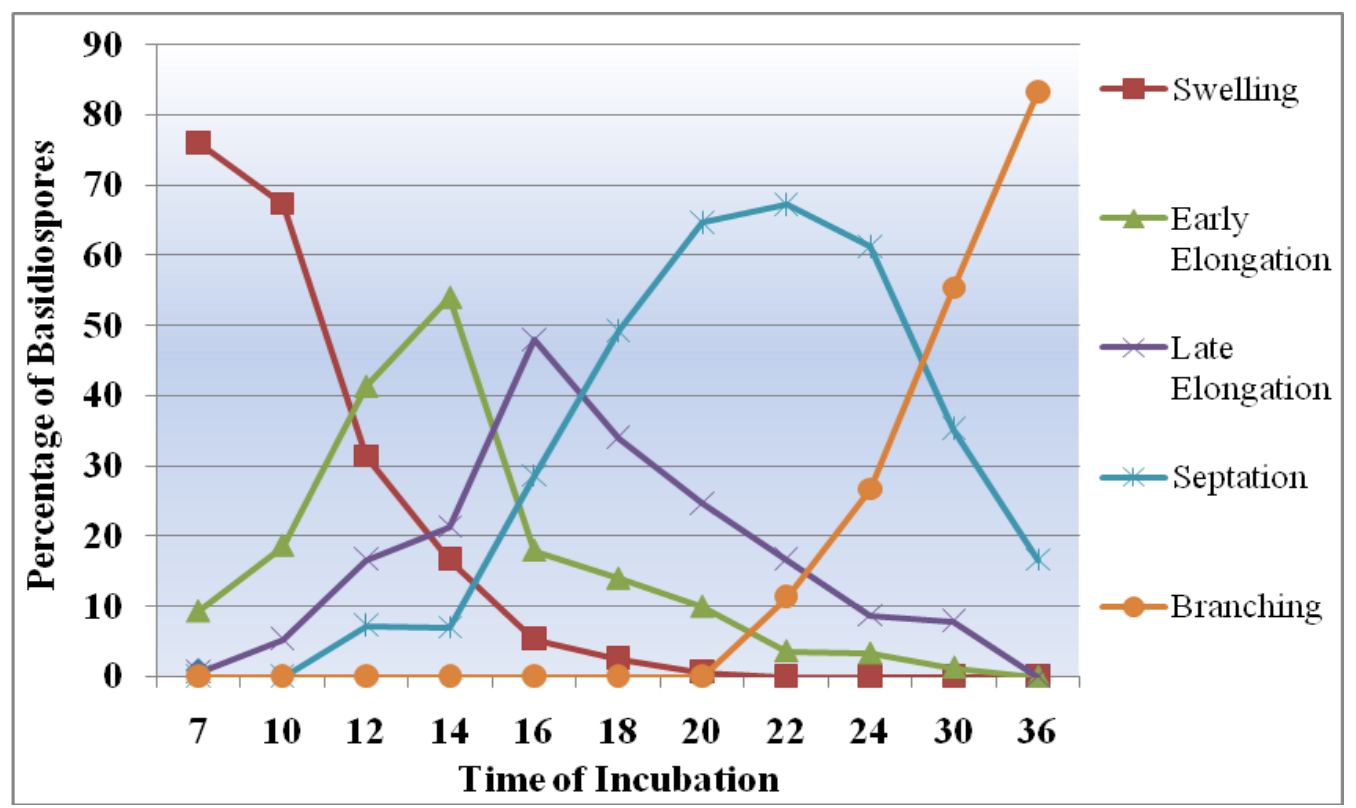

Fig. 1 - Percentage of germinating basidiospores undergoing different morphological stages (swelling, early elongation, late elongation, septation and branching).

light can induce the basidiospore germination. However, the result of the present study does not conform with the observations of Bulseco et al. (2005) and Reyes et al. (1999) who reported that light and dark conditions did not affect basidospore germination of $S$. commune and $V$. volvacea. Furthermore, Chang and Miles (1989) reported that light induces the normal development of mushroom fruiting body.

The results of the assay on the influence of different temperatures on the germination of basidiospores of L. tigrinus are presented in Table 1. Germination of basidiospores was significantly affected by temperature. Basidiospores at $23^{\circ} \mathrm{C}$ (air-conditioned with $48 \%$ relative humidity) recorded the highest percentage germination with means of $86.00 \%$ and $91.33 \%$, after 7 hours and 10 hours, respectively. The lowest percent basidiospore germination was observed at room temperature $\left(32^{\circ} \mathrm{C}\right)$ with means of $50 \%$ and $54 \%$ after 7 hours and 10 hours, respectively. These results are in agreement with the findings of Bulseco et al. (2005) who reported that air-conditioned temperature is the optimum temperature for germination and elongation of basidiospores of $S$. commune. Moreover, the appropriate temperature range for spore germination of $P$. ostreatus was found to be $24-28^{\circ} \mathrm{C}$ (Lin, 2004). It can be noted further that the optimum temperature for basidiospore germination was lower than the optimum temperature for efficient mycelial growth.

\section{Process of basidiospore germination and hyphal growth}

After optimization of the nutritional and environmental conditions for basidiospore germination, the periodic morphological changes from liberation of basidiospore to branching hypha were monitored every 2 hours to determine the time of occurrence of different morphological stages (Figure 1). Swelling of basidiospores commenced after 7-10 hours of incubation when basidiospores imbibed broth medium through their hilum. However, early elongation of basidiospores peaked at 12-14 hours, while late elongation was very evident 16 hours after incubation. During the elongation process, it can be noticed that the spore coat of the basidiospore was retained and became part of the hypha. This peculiar type of germination is similar with the process of spore germination of $S$. commune (Bulseco et al., 2005) but not with $V$. volvacea (Reyes, 1999) where germ tube emerges from the hilum of the basidiospores. On the other hand, septation and branching succeeded after 20-24 hours and 30-36 hours of incubation, respectively. No clamp connections and anastomosis were observed. The results of the present study conformed with those described by Kang (2004) on the oyster mushroom (Pleurotus). 


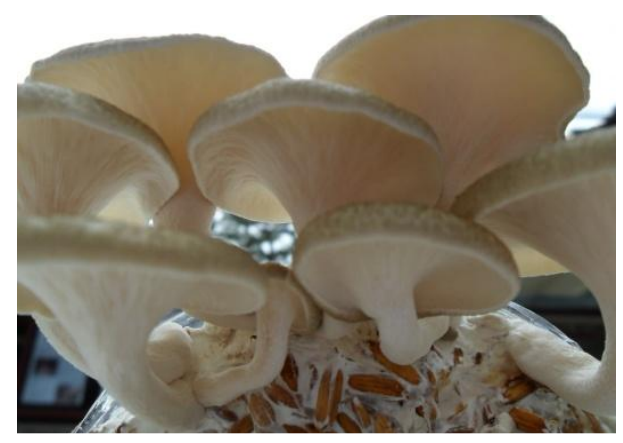

9. Maturation stage (23 d)
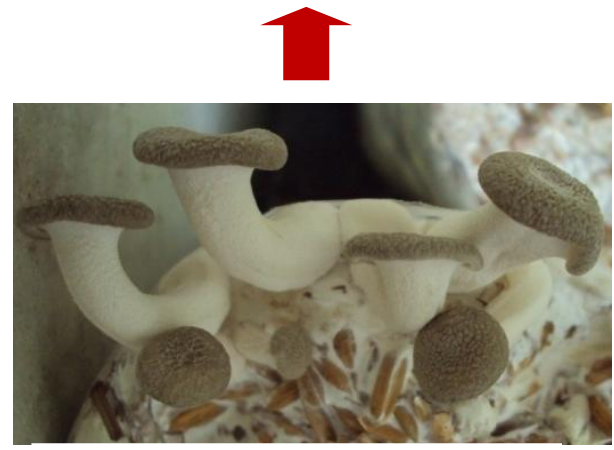

8. Button stage (22 d)

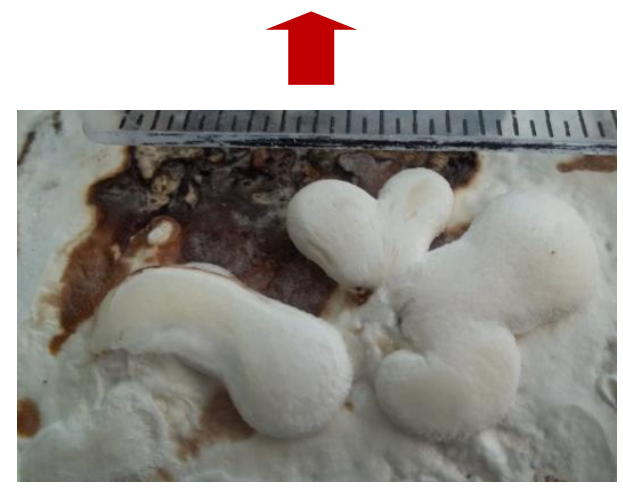

7. Primordia initiation stage $(20 \mathrm{~d})$

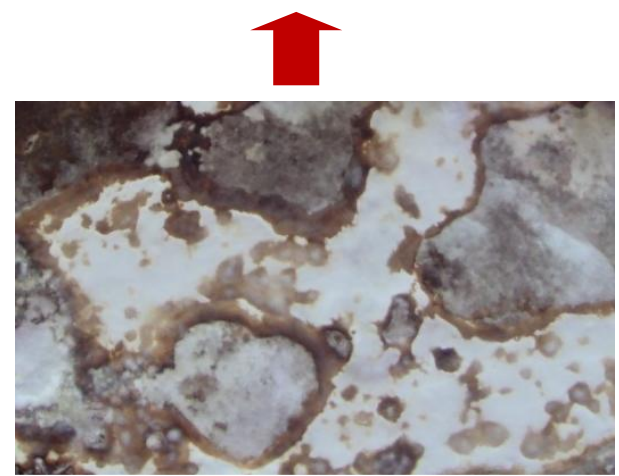

6. Browning and coat hardening (14-18 d)
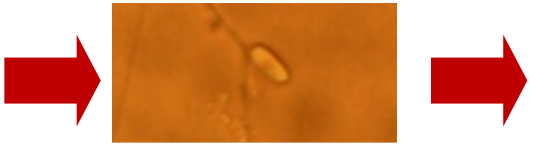

1. Liberated basidiospore

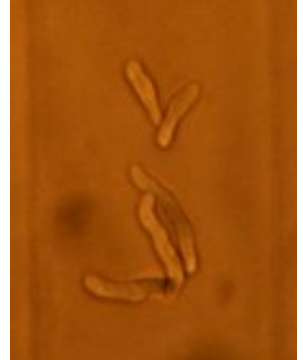

2. Elongation (12-16 h)
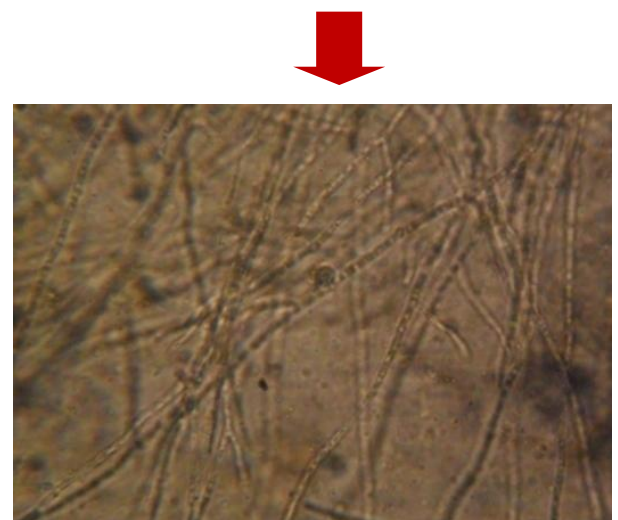

3. Massive branching of hypha (30-36 h)

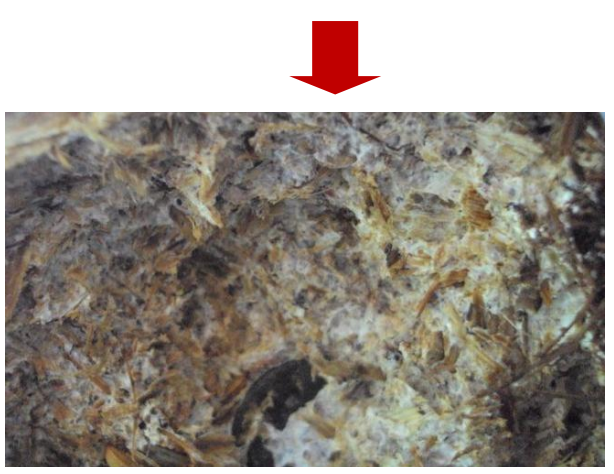

4. Mycelial coat formation (14 d)

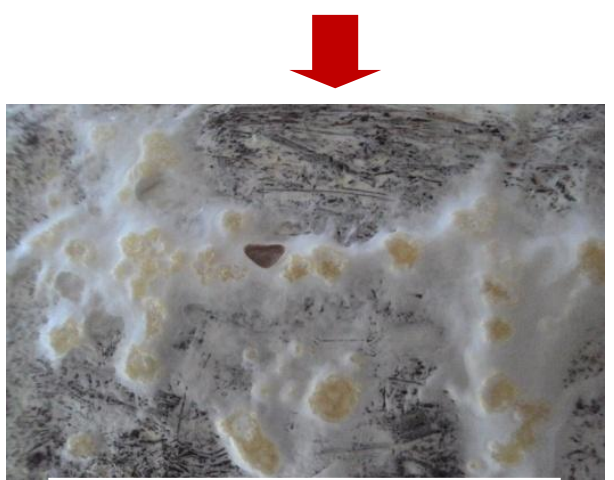

5. Popcorn stage (16 d)

Fig.2 - Morphogenesis of Lentinus tigrinus. 
Four basidiospores formed at the end of each basidium on the gill of a fruiting body having one nucleus. The basidiopores were detached and liberated from the basidia located underneath the fan-shaped pileus. Spores were germinated through swelling, and elongated to become septated hypha, then into primary mycelia in the course of monokaryotization. The primary mycelia were developed into secondary mycelia by dikaryotization or plasmogamy (fusion of hypa) with two nuclei each hypha.

\section{Developmental stages in basidiocarp formation}

The developmental stages of L. tigrinus in the formation of basidiocarps were observed to be divided into nine significant stages (Figure 2). These include: 1. liberation of basidiospores from the mature basidiocarp, 2 . elongation or monokaryotization of primary mycelia, 3. plasmogamy (fusion of hypha) or dikaryotization of mycelia, 4. mycelial coat thickening, 5 . swelling formation (popcorn/blister stage), 6. browning (pigmentation) and coat-hardening formation, 7. formation of fruiting initials (primordia), 8 . stipe elongation of button stage, and 9 . expansion of in-rolled margin of pileus for the liberation of basidiospores. This life cycle of $L$. tigrinus involves both a vegetative phase of spore germination into mycelial growth as discussed in the preceding section (process of basidiospore germination and hyphal growth) and a reproductive phase of fruiting body formation. Immediately after introducing the mycelia into the substrate, the white mycelia began to grow until 7 days (shortest incubation period) of mycelial colonization was completed. Chen (2004) considered that mycelial colonization in the medium is a phase of active fungal metabolism. At the later stage of mycelial ramification, thick mycelial coats on the outer surface of colonized substrate were formed 14 days after inoculation. After 2 days, the popcorn-like swellings on the surface of the thick mycelial coat appeared. Swelling usually form 10 days faster at $25^{\circ} \mathrm{C}$ than $15^{\circ} \mathrm{C}$ (Miles and Chang, 1989) and this formation was due to the high $\mathrm{CO}_{2}$ concentrations and fluctuation of temperature (Chen, 2004). After exposure to air and water, brown pigmentation of the mycelial coat was observed. At the tip of the swelling, primordium formation commenced and developed into young basidiocarp (button stage) with elongated stipe and dark brown pileus. The basidiocarp continued to increase in size and thickness. The pileus at the in-rolled downward margin expanded to liberate the haploid basidiospores.

In this study, the optimum conditions for the germination of basidiospores of $L$. tigrinus with special reference on the nutritional and physical factors were investigated. We elucidated for the first time the morphogenesis of Lentinus tigrinus from the germination of its basidiospores up to the formation of basidiocarp. A sequence of significant developmental stages; swelling and elongation of basidiospores and eventually became part of the hypha, mycelial coat thickening, swelling formation, browning, primordial initiation and basidiocarp development and maturation. Further studies on the evaluation of other indigenous culture media for secondary mycelia of $L$. tigrinus are highly recommended. Works on the elucidation of the nutraceutical attributes of this mushroom is also necessary.

\section{Acknowledgements}

This study was supported by a thesis grant from the Science Education InstituteAccelerated Science and Technology Human Resource and Development Program (SEIASTHRDP) of the Department of Science and Technology in the Philippines.

\section{References}

Bulseco MG, Abella E, Reyes RG. 2005 Morphogenesis of Schizophyllum commune, a wild edible mushroom of Mt. Nagpale, Abucay, Bataan, Philippines. Journal of Nature Studies. 4 (1), 20-28.

Chang S, Miles P. 1989 - Edible mushrooms and their cultivation. CRC Press, Inc. 4178.

Chen A. 2004 - Growing shiitake mushroom. In, Mushroom grower's handbook 1: Oyster mushroom cultivation. Seoul, Korea: MushWorld-Heineart Inc. 248261. 
Dulay RMR, Cabrera EC, Kalaw SP, Reyes RG, Eguchi F. 2011 - Lentinus tigrinus, An Addition to Newly Recorded and Successfully Propagated Wild Strain of Philippine Edible Mushroom. In: Proceedings of the International Unionof Microbiological Societies 2011 Congress pp. 208.

Dulay RMR, Menorca MLR, Gealan PHO, Rubrico EJM, Arenas MC, Kalaw SP, Reyes RG. 2012a - Nutritional value and hypoglycemic effect of Lentinus tigrinus in alloxan-induced mice. In: Proceedings of the Inter-regional Research Conference on Sciences, Technology and the Arts (STArt). pp.10.

Dulay RMR, Pablo FPS, Urbano FG, Kalaw SP, Reyes RG. 2012b - Bactericidal activity of immobilized secondary mycelia of edible mushrooms. In: Proceedings of the Inter-regional Research Conference on Sciences, Technology and the Arts (STArt). pp. 3.

Kang S. 2004 - What is oyster mushroom. In, Mushroom grower's handbook 1: Oyster mushroom cultivation. Seoul, Korea: MushWorld-Heineart Inc. 53-56.

Klomklung N, Karunarathna SC, Chukeatirote E, Hyde KD. 2012 - Domestication of wild strain of Pleurotus giganteus. Sydowia. 64 (1), $39-53$.
Lin Z. 2004 - Grass (Juncao). In, Mushroom grower's handbook 1: Oyster mushroom cultivation. Seoul, Korea: MushWorldHeineart Inc. 107-113.

Miller O. 1973 - Mushrooms of North America. E. P. Dutton, New York. 368.

Niederpruem D, Dennen D. 1966 - Kinetics, nutrition and inhibitor properties of basidiospore germination in Schizophyllum commune. Archives of Microbiology 54(2): 91-105.

Pegler D. 1983 - The genus Lentinus, a world monograph. Kew Bull. add. ser. X. 281.

Reyes R. 1999 - Basic and applied studies for the cultivation of paddy straw mushroom (Volvariella volvacea) from the Philippines. PhD. Dissertation. Tokyo University of Agriculture, Tokyo, Japan.

Singer R. 1986 - The Agaricales in modern taxonomy. 4th Ed. Koeltz Scientific Books, Koenigstein, Federal Republic of Germany. 981.

Thongklang N, Hyde KD, Bussaban B, Lumyong S. 2010 - Culture condition, inoculum production and host response of a wild mushroom, Phlebopus portentosus strain CMUHH121-005. Maejo Int. J. Sci. Technol. 5(3), 413-425.

Velangi F, Wolever A. 2001 - Glycemic index of potatoes commonly consumed in North America. J Am Diet Assoc. 105, 557-562. 